\title{
Analysis of Doctor "Stigmatization" and the Path of Media Image Remodeling
}

\author{
Wang $\mathrm{Li}^{1}$, Chen Sisi ${ }^{1}$, Liao Yawen ${ }^{1}$, Sun Jianqiang ${ }^{1}$, Yu Suzhen*2 \\ 1. Jiangxi University of traditional Chinese medicine \\ 2. Nanchang Institute of Science and Technology
}

\begin{abstract}
Doctor "stigmatization" is an important social phenomenon in China today. This article starts with the concept of stigmatization and its generalization tendency, expounds the origin and influence of doctor "stigmatization", and analyzes the reasons from the generative mechanism of doctor media image. Then the path of remodeling doctor media image is proposed from four perspectives: government, medicals, media and public.
\end{abstract} path

Keywords-Doctor; Media image; Stigmatization; Remodeling

\section{I. "STIGMATIZATION" AND ITS UNIVERSALIZATION}

When the famous 20th-century sociologist Norbert Elias studied a religious cult member, he discovered a phenomenon that a group of people in society are accustomed to imposing the inferiority of human nature on the other group and maintaining it. $\mathrm{He}$ called this "stigmatization". "Stigmatization" derives from the negative abstraction of certain characteristics of a group, while obscuring the rest of other characteristics. Over time, this "label" becomes the counterpart of this group [1].

There were two representative "stigmatization" in history, the "Yellow Peril" theory and Hitler's generalization of Jews. The "Yellow Peril" theory originated in Europe in 19th century, which generally believed that one of the founders of anarchism, the Russian person Bakunin was the initiator. In his book "National Institutions and Anarchy", he emphatically propagated the threat posed by yellow people (Chinese), the British colonialist Pearson further developed and improved this statement and made it basically formed [2]. The German scholar Heinz Gollwitzer believes that "the 'yellow peril' is a slogan in the period of imperialism. To ensure the slogan make effect, the public opinions and factors that stimulate public life emotion are needed; the language should be brilliant and powerful, clear and easy to understand, distort the nature of things, and even become wild so that inspire people or arouse their worries and fears. Hitler believed in racism and dreamed of reviving Germany. He considered extremely that Germany's failure stems from the betrayal of Jews and swore to wipe out all the Jews. He summed up the Jews in one sentence: "Their eyes are brown, mysterious, and you will never understand what is hidden behind them, only physical extermination can relieve my worries!" In order to achieve his political ideal of seizing political power, Hitler lied to the German public that Jews had plundered the nation's wealth and their poverty was caused by the Jews, which greatly deepened the German people's hatred towards Jews [3].
The modernization process of mankind is a process of secularization and democratization, of which the basic value is equality for all. But until today, "stigmatization" has not disappeared and even has continued to emerge in new forms. For example, AIDS patients are labelled ruthlessly as "immoral", "derailment" and "dirty", which develops more and more serious and causes them become "the alien group" so that they are rejected by the society. The "stigmatization" of migrant workers group is that they are always regarded as uncivilized and impolite group, and even their children are regarded as bad students in school. At the same time, under the network communication environment, urban management, doctors, professors, officials, rich people, stars, etc., as well as various "second generations" have also been tagged and "stigmatized". More and more "stigmatization" and "stigmatization" methods of treating or understanding things have a tremendous destructive effect on the entire society and relationship of all kinds of people and places. "stigmatization" is distorting people's normal thinking structure and seems to deconstruct and destroy all positive images. When we use "stigmatization" to construct and arrange the people and events around us, they may really become more and more dirty.

\section{THE ORIGIN OF DOCTOR "STIGMATIZATION"}

In traditional society, doctors often use their own benevolence as a code of conduct, focusing on medical ethics [4]. Since the reform and opening up, Chinese social structure has undergone profound changes. The allocation and operation of resources in many social areas have shifted from planned economy to market economy. The national medical system has also followed the trend of reforms and has lazily copied the reform methods of other industries. The government's direct investment ratio has been decreasing year by year. In 1992, the Ministry of Health proposed the slogan "Building by country and eating by yourself", which directly opened the Pandora's Box where the hospital was engaged in income generation. The medical chaos a few decades later, mostly started from this period. The "using drugs to support medicals" directly leads to two faces in the group of doctors. Speaking of healing the wounded and rescuing the dying, all of doctors are angels; when it comes to income, they are demons. When the media showed this nature of two faces to the entire society, the doctors' media impression also changed from "white angels" to "white wolves". This is also the beginning of the stigmatization of Chinese doctors. 
At present, as a group or vocation "doctors" are being stigmatized and labelled like "white-eyed wolves", "quack doctors", "professional killers" or "red envelope processing machines". The phenomenon of vilifying or even "demonizing" doctors has intensified, which makes doctors encounter social isolation and public hostility and gradually lost their social reputation and professional image. With the constant expansion of the virtual public domain, this phenomenon has gradually spread from the real society to the virtual space. This phenomenon will undoubtedly aggravate conflicts among social classes, seriously undermine the medical ecological environment, hurt the doctor's feeling and dignity, and make the doctor-patient relationship worse. In early 2017, the top medical journal The Lancet announced a study: during the 10 years from 2005 to $2015,4.7$ million medical students has graduated in China, but the total number of doctors only increased by 750,000, the outflow of talent was serious. The ageing of Chinese doctors is prominent. The proportion of young doctors aged 25-34 has dropped from $31.3 \%$ to $22.6 \%$, while the proportion of doctors aged over 60 has increased from $2.5 \%$ to $11.6 \%$, which shows the sense of professional belonging of doctors has been affected by "stigmatization", which will bring huge losses to not only the development of medical and health services but also the entire society.

\section{REASONS FOR DOCTOR "STIGMATIZATION"}

Doctor "stigmatization" inevitably has many in-depth reasons. Here, only two main factors are analyzed from perspective of the formation mechanism of doctor media image.

\section{A. The negative problems in the medical and healthy industry itself}

Compared with how to obtain real news, the authenticity of the news is the most important [5]. The communicator's construction for the doctor image firstly depends on objective facts of its existence, including the negative material for the media provided by the physicians as individuals or as a group, and the medical and healthy industry. For example, the tendency of marketization in the early stage of medical reform led public medical institutions to adopt "using drugs to support medicals" and profit-seeking behaviors are serious, so the incidents of income-generating doctors are seeking unscrupulous interests occurred from time to time; the distribution of medical resources in our country has been uneven for a long time, there is no fundamental change in the lack of medical services in village and substratum., the doctors' credibility is declining due to the difficulty and expensiveness in seeing a doctor, the sense of experience and access to medical services is poor, and the relationship between doctors and patients is gradually becoming tense; medical knowledge and technology have their own limitations, even in today's highly developed medical science, the consensus recognition rate at home and abroad is only about $70 \%$, and the rate of various acute and severe cases is between $70 \%$ and $80 \%$. A considerable part of diseases have unknown causes and difficulty to diagnose, and even there are still high misdiagnosis rate, so treatment is hopeless [6]. However, due to the high expectation from society and public, and the apparent asymmetry of information, it is easy to attribute responsibility to the medicals side. Of course, the occurrence of violations for doctors can easily cause social dissatisfaction, but this problem is not unique to this profession.

\section{B. The variation of the doctor image construction by the media}

News facts are not only the objective facts themselves, but also the communicators' cognitive results. Therefore, to examine the causes of doctor "stigmatization", we must examine the variation of doctor image construction by the mass media. In China, the media industry and the medical industry are also in the junction between complete marketization and non-marketization. One of the important methods of "eyeball economy" is the introduction of attractive news. The news value that "bad news is news" has prompted the media to keep a close eye on negative events and issues in the medical and healthy field, so that the exposure can be increased. As mentioned above, the phenomenon of violating professional ethics is not specific to a certain industry. Some media or media individuals lack individual news literacy, they report incompleteness, subjective judgments, and even intentional distortions in the planning of false news. For many years, many media have reported untruthfully about doctor-patient disputes [7], including black news such as "sew anus", "eight cents", "naked dead", "baked baby", "diarrhea kidney", "leaved gauze" and other a series of media maliciously concocted news. Negative impressions are gradually accumulating in the public's mind, causing the credibility of hospitals and doctors to decline.

\section{PATH OF RESHAPING THE DOCTOR MEDIA IMAGE}

\section{A. The government deepens the reform of medical system and creates a social atmosphere that respects doctors}

The fundamental purpose of the reform in medical system is to solve the problem of difficulty and expensiveness in seeing a doctor, and to fully guarantee the public's right in medical care. For the government department, every decision must firstly be conducive to the development of whole society, not just the interests of a certain local group, which is a principle that any reform must follow. When the medical system reform enters deep water areas, it is necessary to overcome difficulties, resolve deep-level contradictory needs, and give full play to the enthusiasm of the medical staff. We can start with aspects such as improvement of treatment, career development, practice environment and social status to enhance the sense of professional belonging of doctors; perfection of laws and regulations, building healthy public opinion environment, enhancement of professional glory for doctors through various forms, and creating a social atmosphere that respects doctors. 


\section{B. The media abides by professional ethics and reports news in a balanced and fair manner.}

Authenticity is the origin of news, and narrative in an objective position is the most basic professional ethics for the media. If you deviate from an objective position, the "demonization" of doctors will not only infringe the rights of hospitals and doctors, but also misleads the public in the judgment of the doctor image, then intensifies the conflicts between doctors and patients. On the other hand, when the media chooses the news source, if the individual facts are removed from the whole, the content displayed must be onesided and subjective, then the audience's cognition will be deceived [8]. In other words, the media only favors exposing the problems and disadvantages of the medical system, the medical industry and the medical personnel, these criticisms will cause the public to gradually form stereotyped stereotypes, which will be brought into the real experience, amplified, diffused or even stigmatized. Therefore, on the premise of ensuring the truthfulness of news dissemination, the media should fully consider the balance of news source and the balance between economic interests and social responsibilities, enhance professional qualities, view problems from overall situation and reflect the relationship between doctors and patients objectively, fairly and comprehensively.

\section{The medical side strengthens the connotation construction and improves the social communication mechanism}

In today's information-based society and networked communication environment, the phenomenon of aphasia and passive attitude for medical side in dissemination is serious, doctor image is passively constructed by the media. Without the methods and ability of dissemination, doctors are easily to loss of speaking right, which will result in the loss of selfdefinition so that they can only accept the fate of being "neglected" and "defined" [9]. On the one hand, the medical side needs to improve internal management, strengthen connotative construction, improve the quality of medical services, improve service attitudes and enhance the patients' sense of identity, satisfaction and gain; on the other hand, they must actively use mass media tools especially new media, establish advocacy mechanisms, crisis warning mechanisms, news spokesman systems, etc., build the consciousness of proactive communication with the media and the public, routinely conduct positive and right public opinion guidance, and pay attention to establish a good relationship with the news media.

\section{The public promotes media literacy and cultivates rational judgment}

The perceptions, judgments, and attitudes toward doctors from public will determine the relationship between doctors and patients as well as the survival status of doctor profession. In the dissemination environment, the public is integrated into the audiences and communicator, especially in the cybervirtual society, every person is a self-media. The network communication effect is a direct reflection of social communication effect [10]. Media literacy refers to people's ability to interpret and critique various media information and use media information for personal life and social development
[11]. Of course, the medical field is very professional, and the information asymmetry is obvious. The improvement of public media literacy needs to be based on scientific and healthy supply from the whole society. Only when the public has ability to acquire and use information can they treat and distinguish information more reasoningly, reasonably express their opinions on the basis of respecting truth, then ensure the well-organized promotion of public voice with support of sufficient data. This is the right way to cultivate rational judgment of the public.

\section{CONCLUSION}

In the communication environment in which the real world and the cyber world are in harmony, doctors' stigmatization can easily lead to the negative construction and solidification of doctors' images in our country, distorting social cognition, destroying the relationship between doctors and patients, and affecting the healthy development of medical and health services. It is necessary for the government, media, medical authorities, and the public to carry out multi-channel and multipath reconstruction of the doctor's media image.

\section{ACKNOWLEDGMENT}

Foundation project: The project of the humanities and social sciences of universities in Jiangxi: stigmatization of "doctor" media image in Virtual Society (item No.: JC161002)

Corresponding author: Yu Suzhen (278838782@qq.com)

\section{REFERENCES}

[1] Universalization of "stigmatization", First Financial Daily [N], 201405-30

[2] Xu Saifeng. "The Theory of Yellow Peril" and Japanese Diplomacy During the Russo-Japanese War: Viewpoint of Ethnology [J], Journal of Northeast Normal University (Philosophy and Social Sciences), 2014, 4 (270): $12-17$

[3] Liu Feng. Anti-Jewish Reasons for Hitler, New West [J], 2016, 26: 90 91

[4] Xu Ping, Wang Yunling, Cao Yongfu. Research on doctor-patient relationship in ancient China [M]. Jinan: Shandong University Press, 2006: 2 .

[5] Han Juanjuan. Dialectical thinking on Lu Dingyi's basic viewpoint of journalism[J], 2016,7(13):46-47

[6] Wang Hongzhi. Research on variation and reconstruction of doctor's media image[D], Heilongjiang University, 2013

[7] Hou Lin. Analysis of the framework of doctor-patient relationship in Southern Weekend and Qianjiang Evening News [D], Zhejiang Communication Institute, 2016

[8] Liu Jianming. Modern Journalism Theory [M], Beijing: National Publishing House. 1999:60

[9] Guan Zhongxiang. The spread of power, weak voices and the formation of civil society [EB/OL]. China News Research Center website (200208-21). http://www.cddc.net/shownews.asp?newsid=2068.

[10] Qiu Junping, Chen Yuan, Zou Jing. On the role of network community information dissemination in the construction of a harmonious society [J], Shandong Social Sciences, 2008 (5).

[11] Li Huilan. Discussion on employment relationship among media, media literacy and medical graduate students [J], China Coal Industry Medical Journal, 2010, 13 (12):1890-1892 